Volume: 2, Issue: 4, December 2017, Pages: 217-218, DOI: http://dx.doi.org/10.19082/ah217

\title{
ROUTINE SCREENING FOR SYPHILIS: IS IT TIME FOR RECONSIDERATION?
}

\author{
Parivash Davoudian ${ }^{1}$, Hamidreza Mahboobi ${ }^{2}$
}

1: Assistant Professor, Infectious and Tropical Diseases Research Center, Hormozgan University of Medical Sciences, Bandar Abbas, Iran

2: Resident of Internal Medicine, Infectious and Tropical Diseases Research Center, Hormozgan University of Medical Sciences, Bandar Abbas, Iran

\section{TYPE OF ARTICLE: EDITORIAL}

\begin{abstract}
Syphilis is a sexually transmitted disease which is caused by Treponema pallidum. Its prevalence is higher in Africa, South-East Asia, and Western Pacific region. But in Iran, its prevalence is low and several epidemiological studies have reported no case of syphilis during routine screening programs. Also, we know from unpublished data that we have had no cases of syphilis in Hormozgan province for at least 10 years in about 300,000 individuals screened for VDRL. Routine screening for syphilis is associated with high costs to the health system and may be unnecessary in areas with very low incidence of syphilis. However, there is insufficient evidence available for recommendation of deleting routine screening for syphilis in areas with low prevalence of the disease, but it seems that doing large observational studies in these areas can be useful for establishing local protocols for syphilis screening based on the prevalence of disease in each area. In areas with low prevalence of syphilis, we recommend screening of syphilis only in high risk individuals.
\end{abstract}

KEYWORDS: Syphilis, Venereal Disease Research Laboratory (VDRL), Rapid Plasma Reagin (RPR), Screening

Syphilis is a sexually transmitted disease which is caused by Treponema pallidum. The clinical presentation of the disease is different from asymptomatic patients to patients with chancre, diffuse rash, or aortic insufficiency. In the report by the World Health Organization (WHO) in 2012 the prevalence and incidence of syphilis were 18 million, and 5.6 million among the 15 to 49 year-old population worldwide. The prevalence was higher in Africa, South-East Asia, and Western Pacific region. In the United States, the overall number of syphilis cases is increasing. In Iran, the reported prevalence of syphilis is very low. In some provinces, no cases of syphilis are reported. However, in selected populations, variable prevalence is reported. A weighted prevalence of $7.2 \%$ was reported among female sex workers in Kerman (1). Among 70 homeless individuals less than 15 years old, one had a positive RPR test (2). Currently, serologic testing for syphilis is done for symptomatic patients and individuals who are at high risk for the diseases. In addition, routine screening for syphilis is done for pregnant women, before marriage, before employment, for obtaining a health certificate, and before military service. Screening of asymptomatic individuals for syphilis is recommended because the disease often resolves in early stages and can be treated easily, but in later stages the complications are presented and the individuals are at high risk for transmitting the disease. In Iran, usually Venereal Disease Research Laboratory (VDRL) and Rapid Plasma Reagin (RPR) tests are used for routine screening. The positive results need to be confirmed by a fluorescent treponemal antibody absorption (FTA-ABS) test. Syphilis in pregnancy is associated with important complications in the fetus. Therefore, routine screening is recommended before or during pregnancy (3-5). Several researchers have shown the importance of routine screening for syphilis in pregnancy in Iran. However, some studies have reported no positive screening test results among the large population screened for syphilis. For example, no positive screening test result was reported in a study by Esmaeili et al. on 2,0294 blood donors in Bushehr (6). Also in a recent study, we reported no positive VDRL tests on 360 intravenous drug users in Bandar Abbas (7). In a recent study in Tehran, no cases of syphilis were reported among 161 female sex workers in Tehran (8). No case of RPR positive was reported in a study among female prisoners in Isfahan (9). Similar results were reported among street children in Tehran (10). Also, we know from

\section{Correspondence:}

Dr. Hamidreza Mahboobi. Infectious and Tropical Diseases Research Center, Hormozgan University of Medical Sciences, Bandar Abbas, Iran. Tel.: +989172121995, E-mail: hamidrezamahboobi@yahoo.com

Received: January 17, 2017, Accepted: July 13, 2017, Published: December 2017

iThenticate screening: February 01, 2017, English editing: November 12, 2017, Quality control: November 25, 2017

(C) 2017 The Authors. This is an open access article under the terms of the Creative Commons Attribution-NonCommercialNoDerivs License, which permits use and distribution in any medium, provided the original work is properly cited, the use is non-commercial and no modifications or adaptations are made. 
unpublished data that there have been no cases of syphilis in Hormozgan province for at least 10 years in about 300,000 individuals screened for VDRL. Routine screening for syphilis is associated with high costs for the health system, and may be unnecessary in areas with very low incidence of syphilis. Although the test is inexpensive, the large number of individuals screened for this test creates high costs for the health system. One possible explanation for this low rate of positive VDRL is the wide use of antibiotics for sexually transmitted diseases which can lead to treatment of syphilis in incubation period. However, there is insufficient evidence available for recommendation of deleting routine screening for syphilis in areas with low prevalence of syphilis, but it seems that doing large observational studies in these areas can be useful for establishing local protocols for syphilis screening based on the prevalence of disease in each area. Deleting VDRL screening may not be rational in all of the mentioned population, but should be limited to high risk population.

CONFLICT OF INTEREST:

The authors declare that they have no conflict of interests.

\section{FOUNDING:}

NA.

\section{AUTHORS' CONTRIBUTIONS:}

Both authors contributed to this project and article equally. Both authors read and approved the final manuscript.

\section{REFERENCES:}

1) Navadeh S, Mirzazadeh A, Mousavi L, Haghdoost A, Fahimfar N, Sedaghat A. HIV, HSV2 and Syphilis Prevalence in Female Sex Workers in Kerman, South-East Iran; Using Respondent-Driven Sampling. Iran J Public Health. 2012; 41(12): 60-5. PMID: 23641392, PMCID: PMC3640783.

2) Vahdani P, Hosseini-Moghaddam SM, Family A, Moheb-Dezfouli R. Prevalence of HBV, HCV, HIV and syphilis among homeless subjects older than fifteen years in Tehran. Arch Iran Med. 2009; 12(5): $483-7$. PMID: 19722771.

3) Stoner BP. Rapid tests for maternal syphilis screening: effective and cost-effective. Sex Transm Dis. 2008; 35(9): 785-6. doi: 10.1097/OLQ.0b013e31818638ee. PMID: 18665015.

4) Delport SD. On-site screening for maternal syphilis in an antenatal clinic. S Afr Med J. 1993; 83(10): 7234. PMID: 8191323.

5) Delport SD, Ballard RC, Cameron NA, Rothberg AD. Prevention of congenital syphilis by effective maternal screening at antenatal clinics. S Afr Med J. 1993; 83(10): 710-1. PMID: 8191313.

6) Esmaeili H, Hajiani G, Monkhian A, Pourmahdi Boroujeni M. Seroepidemiological survey of hepatitis B, C, HIV and syphilis among blood donors in Bushehr-Iran. Iranian South Medical Journal. 2009; 11(2): 183-90.

7) Davoodian D, Dadvand H, Mahoori K, Amoozandeh A, Salavati A. Prevalence of Selected Sexually and Blood-Borne Infections in Injecting Drug Abuser Inmates of Bandar Abbas and Roodan Correction Facilities, Iran, 2002. BJID. 2009; 13: 356-8.

8) Moayedi-Nia S, Bayat Jozani Z, Esmaeeli Djavid G, Entekhabi F, Bayanolhagh S, Saatian M, et al. HIV, $\mathrm{HCV}, \mathrm{HBV}, \mathrm{HSV}$, and syphilis prevalence among female sex workers in Tehran, Iran, by using respondent-driven sampling. AIDS Care. 2016; 28(4): 487-90. doi: 10.1080/09540121.2015.1109582. PMID: 26565671.

9) Nokhodian Z, Yazdani MR, Yaran M, Shoaei P, Mirian M, Ataei B, et al. Prevalence and Risk Factors of HIV, Syphilis, Hepatitis B and C Among Female Prisoners in Isfahan, Iran. Hepat Mon. 2012; 12(7): 4427. doi: 10.5812/hepatmon.6144. PMID: 23008724. PMCID: PMC3437455.

10) Vahdani P, Hosseini-Moghaddam SM, Gachkar L, Sharafi K. Prevalence of hepatitis B, hepatitis C, human immunodeficiency virus, and syphilis among street children residing in southern Tehran, Iran. Arch Iran Med. 2006; 9(2): 153-5. PMID: 16649359. 